\title{
Thermal properties and flammability of nanocomposites based on diene rubbers and naturally occurring and activated halloysite nanotubes
}

\author{
Przemysław Rybiński • Grażyna Janowska • \\ Małgorzata Jóźwiak • Agnieszka Pająk
}

Received: 16 March 2011 / Accepted: 1 July 2011 / Published online: 19 July 2011

(C) The Author(s) 2011. This article is published with open access at Springerlink.com

\begin{abstract}
This article presents a procedure of the activation of halloysite and a method of the synthesis of nucleus-sheath type filler. The effects of the nanoadditives obtained on the thermal properties, flammabilities and fire hazards of peroxide and sulfur vulcanizates of NBR and SBR rubbers, are discussed. Based on the test results obtained by derivatography, oxygen index, FAA microcalorimeter and cone calorimeter, the thermal stability, flammability, and fire hazard of the nanocomposites investigated were determined. The results obtained were interpreted from the point of view of the chemical structure of the diene elastomers investigated, their spatial network structure, and the method of halloysite modification.
\end{abstract}

Keywords Halloysite - Thermal stability - Vulcanizate of diene rubbers - Flammability $\cdot$ Fire hazard

\section{Introduction}

Along with the development of nanotechnology, everincreasing interest has been focused on nanofillers, such as nanosilica, zinc nanooxide, or natural aluminosilicates, which are now successfully used in both elastomeric composites and thermoplastics.

P. Rybiński $(\square) \cdot$ M. Jóźwiak

Department of Management and Protection Environment,

Jan Kochanowski University of Humanities and Sciences

in Kielce, Kielce, Poland

e-mail: przemek100@ujk.kielce.pl

G. Janowska · A. Pająk

Institute of Polymer and Dye Technology,

Technical University of Łódź, Lodz, Poland
Polymeric composites containing appropriately modified nanofillers show considerably better functional properties compared with traditional materials. Even a low quantity of a nanoadditive (1-8 phr) incorporated into a polymeric matrix allows one to obtain materials with specific properties, i.e., resistant to the action of considerably lowered or elevated temperatures, showing good mechanical properties, as well as reduced flammability and fire hazard. Both the reduced flammability and fire hazard are of paramount importance from the point of view of health and life protection as well as for economic reasons.

In recent years, polymeric nanocomposites containing modified montmorillonites have been a subject of many research and implementation studies [1-3]. So far, however, not much attention has been devoted to naturally occurring aluminosilicate nanotubes. Their use in elastomeric matrix remains largely unexamined.

Halloysite $\left(\mathrm{Al}_{2}\left[\mathrm{Si}_{2} \mathrm{O}_{5}(\mathrm{OH})_{4}\right] \cdot 2 \mathrm{H}_{2} \mathrm{O}\right)$ is a mineral combining the chemism and rigidity of montmorillonite with the geometry of carbon nanotubes [4, 5]. A halloysite nanotube (HNT) occurs in the form of two-layer aluminosilicate. Two tetrahedral silica layers are octahedrally connected with aluminum atoms, resulting in a cylindrical shape of HNT particles [6, 7].From a mineralogical point of view, halloysite is a mineral, similar to kaolin and is a weathering product of granitic and rhyolitic volcanic rocks [8]. The length of HNTs varies from 1 to $15 \mu \mathrm{m}$ and their diameter from 10 to $150 \mathrm{~nm}$. Therefore, halloysite is characterized by a high coefficient of shape (L/D ratio) [4-7], and consequently, when incorporated into a polymeric matrix, it shows a considerably larger surface of polymer-filler interaction in relation to conventional fillers. Hence, it reduces the oscillation of polymer chain segments, bringing about an increase in degradation and destruction temperatures of polymers filled with halloysite. 
This article presents the results of assessing the effect of halloysite activated with sulfuric acid on the thermal stability and flammability of crosslinked diene rubbers. An intercalated halloysite was also used to prepare a filler of nucleus-sheath type.

\section{Experimental}

Materials

We examined the following diene rubbers: butadiene-styrene rubber, KER 1500 , containing $23.5 \%$ of combined styrene, from Synthos S.A, and butadiene-acrylonitrile rubber, NBR $2255 \mathrm{~V}$, containing $22 \%$ of combined acrylonitrile from Bayer.

The rubbers were crosslinked by means of dicumyl peroxide (DCP) in the presence of zinc oxide $(\mathrm{ZnO})$, or with the use of sulfur in the presence of $\mathrm{ZnO}$ and $\mathrm{N}$-cyclohexyl-2benzoyl sulfenamide (Tioheksam CBS). The peroxide vulcanizates of butadiene-styrene and butadiene-acrylonitrile rubbers were denoted with $\mathrm{SN}$ and $\mathrm{NN}$ symbols, respectively. The sulfur vulcanizates of butadiene-styrene and butadiene-acrylonitrile rubbers were denoted with SS and NS symbols, respectively.

Halloysite derived from Dunino deposit, near Legnica (Poland), was used as a filler of elastomeric blends. The chemical composition of this aluminosilicate, before and after its acidic activation, was determined by means of a micro-analyzer, type EDS EDAX Genesis XM 4i (USA), used in a Quanta 250 FEG electron microscope. The activation of halloysite with a $30 \% \mathrm{H}_{2} \mathrm{SO}_{4}$ for 20 min was performed to expose HNTs by removing higher aluminosilicate acids (so-called allophane acids) from their surface and space between them as shown in Fig. 1.

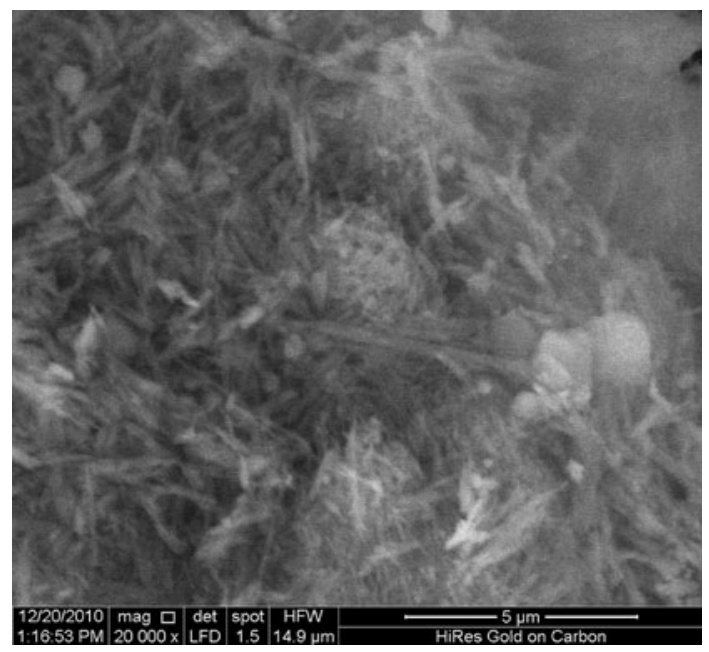

Fig. 1 Halloysite from Aldrich
The nucleus-sheath type filler of a new generation was prepared by the plasticization of acid-intercalated halloysite with chlorosulfonated polyethylene (CSM), Hypalon 30, containing $43 \%$ of combined chlorine, provided by DuPont Dow Elastomers. The resultant premix masterbatch was then heated in a Nabertherm muffle furnace under a neutral gas up to $350{ }^{\circ} \mathrm{C}$. The chlorine content in this filler was $7.53 \%$ by wt. [9].

\section{Methods}

Non-intercalated and intercalated halloysites were assessed by means of a Quanta 250 FEG electron microscope (FEI Company) equipped with electron gun and field emission (Schottky's emitter).

Elastomeric blends were prepared at room temperature by means of a laboratory roll mill, followed by vulcanization in steal molds placed between electrically heated press plates. The optimal time of vulcanization $(\tau 0.9)$ at a temperature of $160{ }^{\circ} \mathrm{C}$ was determined by means of a WG2 vulcameter according to Standard PN-ISO 3417:1994.

The thermal properties of halloysite and halloysite-containing vulcanizates were tested under air atmosphere within the temperature range of $25-800{ }^{\circ} \mathrm{C}$, by means of a Paulik, Paulik, Erdey derivatograph, using $\mathrm{Al}_{2} \mathrm{O}_{3}$ as a reference substance. The heating rate for a sample of weight $90 \mathrm{mg}$ was $7.9^{\circ} \mathrm{C} / \mathrm{min}$, and the sensitivities of thermal curves were as follows: $T G=100, D T A=1 / 5$, and $D T G=1 / 30$.

The flammability of vulcanizates was determined by the method of oxygen index (OI) using an apparatus from Fire Testing Technology Limited. For flammability tests, $50 \times 10 \times 4 \mathrm{~mm}$ samples were prepared. Using a constant nitrogen flow rate amounting to $40 \pm 2 \mathrm{~mm} \times \mathrm{s}^{-1}$, through a test column with a diameter of $75 \mathrm{~mm}$, the oxygen concentration was selected so that the sample under testing was burned within time, $t=180 \mathrm{~s}$. The sample top was ignited for $5 \mathrm{~s}$ by means of a propane-butane gas burner. The numerical value of OI was calculated from the following formula:

$\mathrm{OI}=\left(C_{\mathrm{F}}+k \times d\right) \div 100$

where $C_{\mathrm{F}}$ is the final oxygen concentration, at which a sample is burned within $180 \mathrm{~s} ; d$ is the step size between oxygen concentration changes during the test procedure; $k$ is the coefficient of proportionality.

We also tested flammability in air using identical samples as in the case of OI method. A sample in a vertical position was ignited with a gaseous burner as before for $5 \mathrm{~s}$, and its combustion time $\left(T_{\mathrm{s}}\right)$ was measured.

The vulcanizates under investigation were examined by means of an FAA micro-calorimeter from Fire Testing Technology Limited. The temperature of pyrolyzer was $750{ }^{\circ} \mathrm{C}$, while that of combustor was $900{ }^{\circ} \mathrm{C}$. During measurement, the following parameters were recorded: ignition 
Table 1 Results of elementary analysis of halloysite

\begin{tabular}{lllclll}
\hline Sample & $\mathrm{C} / \%$ & $\mathrm{Al} / \%$ & $\mathrm{Si} / \%$ & $\mathrm{Fe} / \%$ & $\mathrm{O} / \%$ & $\mathrm{~S} / \%$ \\
\hline Halloyiste & 46 & 9 & 8 & 3 & 34 & - \\
Activated halloysite & 24 & 6.7 & 25.3 & 1.9 & 41 & 1.1 \\
\hline
\end{tabular}

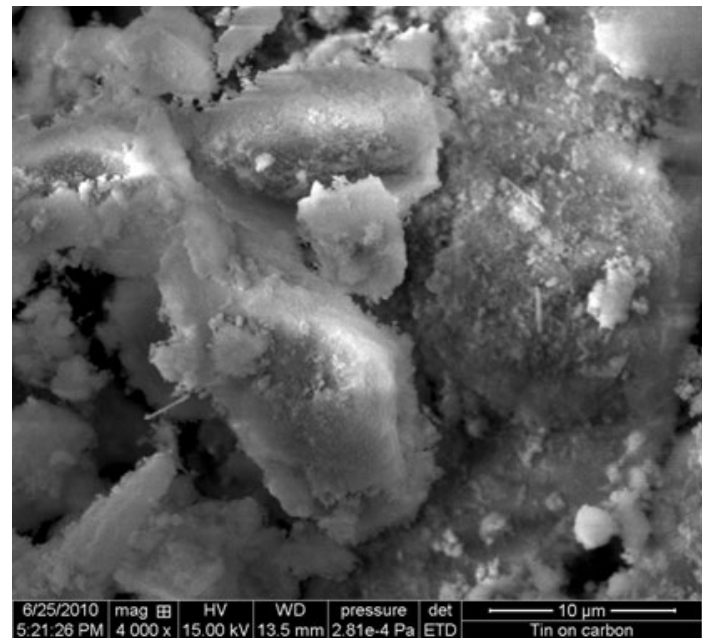

Fig. 2 Non-activated halloysite

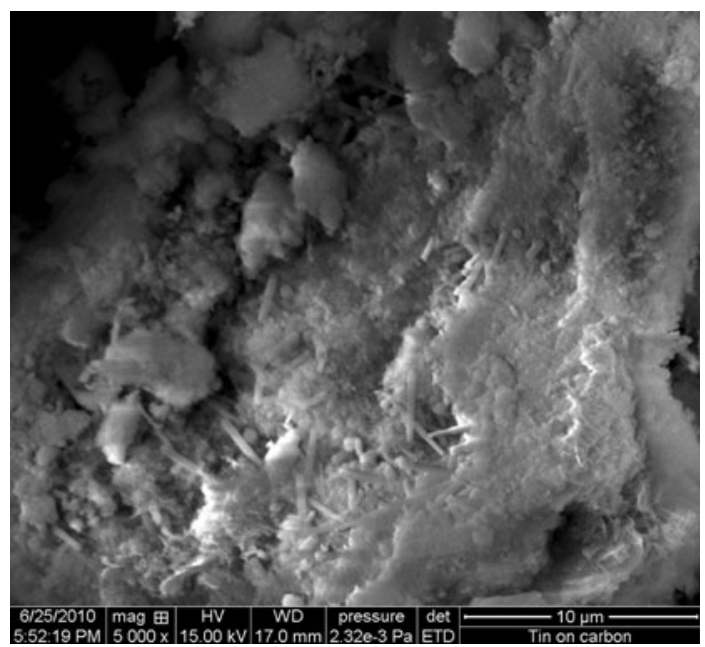

Fig. 3 Activated halloysite

temperature, maximal heat emission rate, total heat emitted, heat capacity, and percentage oxygen consumption.

Selected samples were tested using a cone calorimeter from Atlas Electric Devices Company.

\section{Results and discussion}

The activation of halloysite with a $30 \% \mathrm{H}_{2} \mathrm{SO}_{4}$ for $20 \mathrm{~min}$ was performed to expose HNTs by removing higher

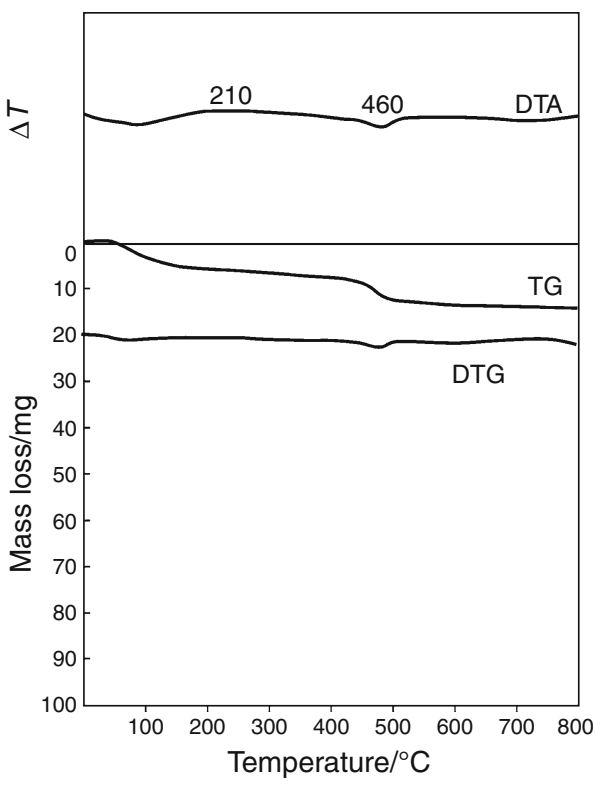

Fig. 4 TG, DTG, and DTA curves of activated halloysite

aluminosilicate acids from their surfaces and spaces between them as shown in Fig. 1 .

Based on the results obtained using EDS micro-analyzer, it was found that the intercalation of halloysite performed in this study changed its elementary composition (Table 1).

The unmodified halloysite contains considerable amounts of carbon and iron (Table 1). Carbon in the form of carbonates and overall organic carbon is on the surface of aluminosilicate; therefore, the surface-performed elementary analysis of non-activated halloysite indicates only $8 \%$ silicon content in it. The intercalation of halloysite with sulfuric acid removes considerable amounts of carbon and iron salts from its surface, which exposes the tubular structure of halloysite as indicated by both the considerable increase in silicon content by about $320 \%$ compared to nonactivated halloysite (Table 1) and the electron microscopy photos (Figs. 2, 3).

During activation with acid, besides the overall organic carbon, a considerable portion of aluminosilicate acids is washed out, which decreases the percentage contents of aluminum and silicon in the activated halloysite sample analyzed. It is not unlikely that some nanotubes are destroyed during the acidic intercalation.

From the derivatographic analysis of activated halloysite, it follows that it undergoes clear three-stage decomposition within the temperature range of $30-700{ }^{\circ} \mathrm{C}$ (Fig. 4). Its first stage of thermal decomposition taking place at $\Delta T_{1}=30-100{ }^{\circ} \mathrm{C}$, accompanied by the endothermic process recorded in DTA curve, is due to desorption of water $(5.5 \%)$ combined with the aluminosilicate surface. The second stage of thermal decomposition 
proceeds at $\Delta T_{2}=100-420{ }^{\circ} \mathrm{C}$, being connected with the release of water physically occluded in nanotubes, as well as water chemically combined with the halloysite surface. This stage is accompanied by a sample weight loss of $3.4 \%$. The final stage of thermal decomposition at $\Delta T_{3}=420-700{ }^{\circ} \mathrm{C}$ is connected with the combustion of the carbon fraction occurring in the form of carbonates and overall aromatic carbon. This stage is accompanied by a sample weight loss of about $6 \%[4,10]$.

The results of thermal examinations show that the characteristics of DTA, TG, and DTG curves of crosslinked elastomers, such as butadiene-acrylonitrile (NBR) or butadiene-styrene copolymer (SBR), are not significantly affected by the spatial network structure and the content of nanoadditive (Fig. 5). On the other hand, the thermal stabilities of elastomers depends on the method of crosslinking, and hence on the spatial network structure [11, 17]. The use of sulfur as a crosslinker leads to the formation of crosswise sulfide bonds that are considerably weaker than the carbon-carbon bonds resulting from the crosslinking by means of dicumyl peroxide. The thermal stabilities of the peroxide vulcanizate of nitrile rubber $(\mathrm{NN})$ and the peroxide vulcanizate of SBR rubbers (SN) determined with coefficient $T_{5}$, are higher by $50{ }^{\circ} \mathrm{C}$ than those of sulfur vulcanizates denoted with NS (sulfur vulcanizate of NBR rubber) and SS (sulfur vulcanizate of SBR rubber), but when expressed by $T_{50}$, they are higher by about $20{ }^{\circ} \mathrm{C}$ (Table 2).

The results of derivatographic analysis listed in Table 2 show that activated halloysite does not unmistakably influence the thermal stabilities of the vulcanizates investigated. In most of the cases, the aluminosilicate used does not significantly change the thermal stabilities of the vulcanizates determined with coefficients $T_{5}$ and $T_{50}$.

It is the thermal decomposition rate that is an important parameter determining both the thermal stability of a polymeric material and its flammability. The decrease in the destruction rate of polymeric nanocomposites exerts a positive influence on the reduction in their flammability. This is due to the formation of lower amounts of volatile and flammable products of pyrolysis passing to flame, which reduces the rate of free-radical reactions proceeding within the combustion zone $[12,13]$.

The effect of activated halloysite on the thermal decomposition rates of the vulcanizates investigated is very clear regardless of the structure of their spatial network. A considerable decrease in the thermal decomposition rate takes place especially in the case of the nanocomposites of nitrile rubber (Table 2).

A positive influence on the thermal decomposition rates of the vulcanizates of both nitrile rubbers (NSN8, and NSN15) and butadiene-styrene rubbers (SSN8, and SSN15), is exerted by the nucleus-sheath-type filler prepared for this study. Under the influence of this filler, not only the destruction rate of vulcanizates is decreased, but also the value of thermal decomposition residues is considerably increased, $P w$ (Table 2). The increased value of this parameter causes a decrease in the amount of destruction products passing to the flame, which reduces the yield of chemical reactions. a

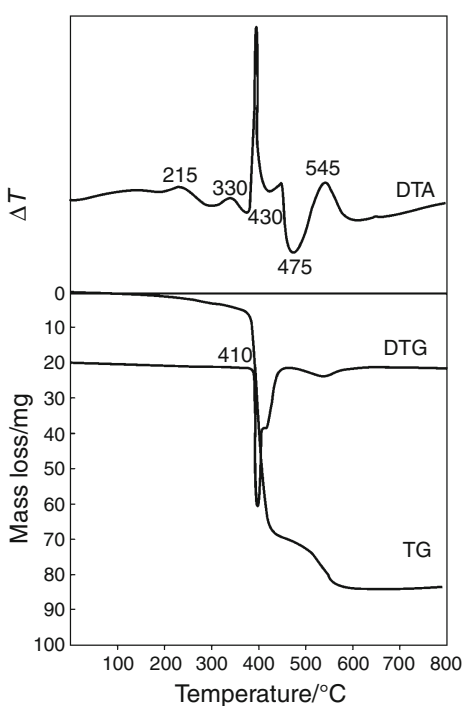

b

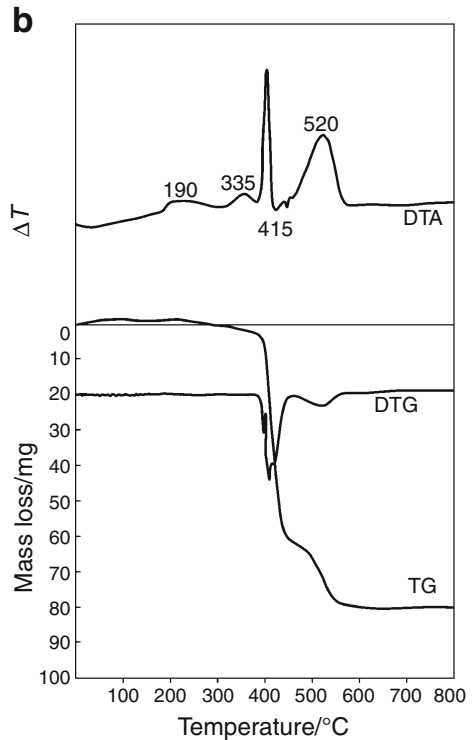

c

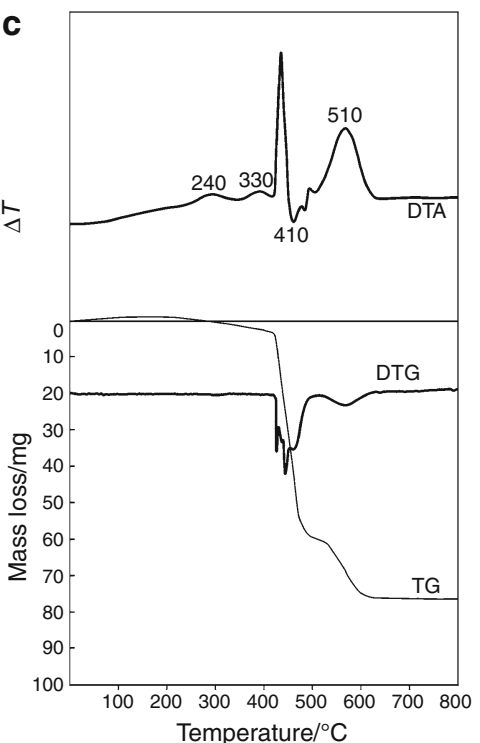

Fig. 5 TG, DTG and DTA curves. a Peroxide vulcanizate of NBR rubber, NN. b Peroxide vulcanizate of NBR rubber containing 5 phr of actived halloysite, NNH5. c Sulfur vulcanizate of NBR rubber containing 5 phr of activated halloysite, NSH5 
Table 2 Thermal analysis of vulcanizates of NBR and SBR rubbers

\begin{tabular}{|c|c|c|c|c|c|c|c|c|}
\hline Sample & $T_{5} /{ }^{\circ} \mathrm{C}$ & $T_{50} /{ }^{\circ} \mathrm{C}$ & $\mathrm{dm} / \mathrm{dt} / \mathrm{mm}$ & $T_{\mathrm{R}} /{ }^{\circ} \mathrm{C}$ & $T_{\mathrm{Rmax}} /{ }^{\circ} \mathrm{C}$ & $P w / \%$ & $T_{\mathrm{s}} /{ }^{\circ} \mathrm{C}$ & $P_{800} / \%$ \\
\hline NN & 350 & 420 & 70 & 390 & 410 & 23 & 545 & 9 \\
\hline NNH5 & 390 & 420 & 57 & 370 & 410 & 24.5 & 510 & 11.1 \\
\hline NS & 315 & 405 & 52 & 370 & 395 & 23 & 540 & 7 \\
\hline NSH5 & 370 & 415 & 46 & 380 & 400 & 27 & 530 & 10.0 \\
\hline NSH8 & 380 & 420 & 45 & 380 & 400 & 32 & 530 & 15.5 \\
\hline NSH15 & 360 & 415 & 45 & 370 & 400 & 31 & 530 & 16 \\
\hline NSN8 & 370 & 415 & 50 & 380 & 410 & 26.5 & 530 & 7.8 \\
\hline NSN15 & 370 & 415 & 50 & 370 & 410 & 32 & 530 & 11.1 \\
\hline $\mathrm{SN}$ & 350 & 419 & 80 & 365 & 415 & 19 & 475 & 5 \\
\hline SNH5 & 360 & 410 & 76 & 370 & 400 & 20 & 480 & 7 \\
\hline SS & 300 & 400 & 70 & 350 & 365 & 20 & 490 & 8.8 \\
\hline SSH5 & 320 & 400 & 70 & 350 & 370 & 20 & 480 & 8.9 \\
\hline SSH8 & 320 & 390 & 65 & 350 & 390 & 23 & 480 & 11.1 \\
\hline SSH15 & 360 & 400 & 75 & 360 & 400 & 21 & 470 & 10 \\
\hline SSN8 & 350 & 410 & 65 & 405 & 400 & 22 & 500 & 7.7 \\
\hline SSN15 & 330 & 400 & 65 & 460 & 400 & 23 & 480 & 8.8 \\
\hline
\end{tabular}

$T_{5}$ and $T_{50}$ are the temperatures of sample 5 and $50 \%$ mass loss, respectively, $d m / d t$ is the maximum rate of thermal decompositions of vulcanizates, $T_{R}$ is the initial temperature of thermal decompositions of vulcanizates, $T_{R \max }$ is the temperature of maximum rate of thermal decomposition of vulcanizate, $P w$ is the residue after the thermal decomposition of vulcanizate, $T s$ is the temperature of residue burning after the thermal decomposition of vulcanizate, $P_{800}$ is the residue after heating up to $T=800{ }^{\circ} \mathrm{C}, N N$ is the peroxide vulcanizate of NBR rubber, $N N H 5$ is the vulcanizate NN containing 5 parts by wt. of halloysite per 100 parts by wt. of NBR, NS is the sulfur vulcanizate of NBR rubber, NSHX is the vulcanizate $N S$ containing $X$ parts by wt. of halloysite per 100 parts by wt. of NBR, where $X=5,8,15$, NSNX is the vulcanizate NS containing X parts by wt. of nucleus-sheath type filler per 100 parts by wt. of NBR, where $X=5,8,15, S N$ is the peroxide vulcanizate of SBR rubber, $S N H 5$ is the vulcanizate $S N$ containing 5 parts by wt. of halloysite per 100 parts by wt. of SBR, $S S$ is the sulfur vulcanizate of SBR rubber, $S S H X$ is the vulcanizate $S S$ containing $X$ parts by wt. of halloysite per 100 parts by wt. of SBR, where $X=5,8,15, S S N X$ is the vulcanizate SS containing $X$ parts by wt. of nucleus-sheath type filler per 100 parts by wt. of SBR, where $X=5,8,15$

High $P w$ values are also observed in the case of the composites of nitrile rubber containing activated halloysite, while in the case of the vulcanizates of butadiene-styrene rubber, this parameter is practically unchanged. Therefore, it can be stated that halloysite facilitates the processes of thermal cyclization and nitrile rubber carbonization, which during its combustion is revealed by the formation of a thermally stable boundary layer impeding the flow of mass and energy between flame and sample. Halloysite fails to intensify carbonization processes taking place during the combustion of the composites of SBR rubber.

The results of derivatographic analysis also indicate a possibility of creating a boundary layer during the combustion of vulcanizates containing our filler (Table 2). Carbon particles present on the surface of aluminosilicate can facilitate the cyclization and thermal crosslinking of elastomer as well as fulfill the role of sorbents of volatile decomposition products.

The analysis of flammability test results leads us to conclude that both the activated halloysite and the filler obtained from it decrease the flammability of elastomers regardless of the structure of their spatial network (Table 3).
The increase in the halloysite content in elastomer nanocomposite is accompanied by the decrease in its flammability expressed by OI, combustion time in air $\left(T_{\mathrm{S}}\right)$ as well as the maximal heat emission rate $\left(\mathrm{HRR}_{\max }\right)$. It should be noticed that the radical decrease in parameter $\mathrm{HRR}_{\text {max }}$ takes place in the case of samples containing the nucleus-sheath filler (vulcanizates denoted with symbols SN8, NSN15, SSN8 and SSN15). In the case of the sulfur vulcanizate of SBR rubber containing the synthesized filler (SSN15), the maximal heat emission rate was reduced by more than $35 \%$ in relation to the unfilled sulfur vulcanizate of this polymer.

From the relevant literature data it follows that the reduction in polymer flammability results first of all from

- the formation of thermally stable isolating boundary layer,

- the reduction in the surface of contact between air and flammable gases resulting from polymer destruction,

- the modification of free-radical reactions taking place in the gaseous phase of combustion,

- decreased surface of the polymer-flame contact, 
Table 3 Flammability test results of vulcanizates of NBR and SBR rubbers

\begin{tabular}{|c|c|c|c|c|c|c|c|c|}
\hline Sample & OI & $\begin{array}{l}\text { Combustion } \\
\text { timein air/s }\end{array}$ & $\mathrm{Tz} /{ }^{\circ} \mathrm{C}$ & $\mathrm{HRR}_{\max } / \mathrm{W} / \mathrm{g}$ & $\begin{array}{l}\text { Total } \\
\mathrm{HR} / \mathrm{kJ} / \mathrm{g}\end{array}$ & HR Capacity/J/g $\times \mathrm{K}$ & Loss mass $/ \%$ & $\begin{array}{l}\text { Oxygen } \\
\text { consumption } / \%\end{array}$ \\
\hline NN & 0.205 & 276 & 357 & 472 & 34.0 & 479 & 11.47 & 50.02 \\
\hline NNH5 & 0.220 & 336 & 362 & 413 & 30.4 & 423 & 7.11 & 45.86 \\
\hline NS & 0.215 & 289 & 366 & 432 & 32.0 & 432 & 9.46 & 67.09 \\
\hline NSH5 & 0.220 & 300 & 365 & 413 & 30.7 & 418 & 7.73 & 47.80 \\
\hline NSH8 & 0.225 & 336 & 369 & 396.1 & 29.8 & 399 & 9.01 & 29.33 \\
\hline NSH15 & 0.237 & 385 & 366 & 391.0 & 29.7 & 398 & 19.8 & 44.20 \\
\hline NSN8 & 0.245 & 370 & 363 & 345.4 & 31.3 & 412 & 4.13 & 29.52 \\
\hline NSN15 & 0.255 & 400 & 366 & 350 & 31.2 & 420 & 9.80 & 39.21 \\
\hline SN & 0.210 & 194 & 350 & 450 & 34.5 & 501 & 21.11 & 40.11 \\
\hline SNH5 & 0.215 & 284 & 357 & 356.7 & 30.5 & 353 & 1.26 & 30.94 \\
\hline SS & 0.220 & 273 & 355 & 399.8 & 34.3 & 397 & 14.31 & 44.91 \\
\hline SSH5 & 0.230 & 319 & 369 & 367.2 & 31.8 & 363 & 8.32 & 39.71 \\
\hline SSH8 & 0.236 & 325 & 365 & 380.1 & 32.3 & 382 & 21.33 & 52.08 \\
\hline SSH15 & 0.250 & 345 & 360 & 370.3 & 31.5 & 370 & 19.8 & 44.26 \\
\hline SSN8 & 0.257 & 341 & 374 & 359.1 & 35.5 & 358 & 9.04 & 40.27 \\
\hline SSN15 & 0.262 & 327 & 387 & 257.7 & 31.7 & 336 & 6.04 & 39.80 \\
\hline
\end{tabular}

$T z$ temperature of ignition, $H R R_{\max }$ maximum heat release rate

- the increased contents of non-flammable gaseous products such as water vapor or hydrohalide in the gaseous products of the polymer thermal decomposition $[14,15]$.

Both from the literature and our studies, it follows that the barrier properties of the halloysite nanotubes used in this study play a great role in reducing the flammability of nanocomposites. Aluminosilicate is impermeable for vapors and gases, and so during the thermal decomposition of nanocomposite, the low-molecular products due to thermal decomposition can diffuse outside elastomer only through closely defined spaces between nanotubes (the so-called channel effect) [16, 17].

The diffusion of oxygen into nanocomposite is also considerably impeded, as indicated by the value of percentage oxygen consumption (Table 3), which reduces the yield of radical degradation reactions and polymer depolymerization during its combustion, consequently increasing its resistance to the action of flame [18].

We believe that, apart from barrier effects, the lumen of the HNTs plays the leading role in decreasing the flammability of the nanocomposites. During the initial degradation stage of nanocomposites the degradation products of vulcanizates of diene rubbers may considerably be entrapped into the lumens of HNTs, resulting in higher randomness of lumen ends. The lumen could, therefore, entrap the degradation products more effectively [19].

From the results of elementary analysis, it follows that the filler obtained by us contains $7.53 \%$ by weight of
Table 4 Mean values of the parameters of SBR rubber vulcanizates determined by means of cone calorimeter

\begin{tabular}{|c|c|c|}
\hline Sample & SS & SSH8 \\
\hline $\begin{array}{l}\text { Time to sustained ignition } \\
\text { (TTI) }[\mathrm{s}]\end{array}$ & 55.01 & 51.86 \\
\hline $\begin{array}{l}\text { Total heat release }(\mathrm{THR}) \\
{\left[\mathrm{MJ} \times \mathrm{m}^{-2}\right]}\end{array}$ & 73.37 & 71.97 \\
\hline $\begin{array}{l}\text { Peak heat release rate }\left(\mathrm{HRR}_{\max }\right) \\
{\left[\mathrm{kW} \times \mathrm{m}^{-2}\right]}\end{array}$ & 1391.71 & 1094.59 \\
\hline $\begin{array}{l}\text { Average heat release rate } \\
{\left[\mathrm{kW} \times \mathrm{m}^{-2}\right]}\end{array}$ & 414.07 & 403.06 \\
\hline $\begin{array}{l}\text { Average heat release rate }(\mathrm{HOC}) \\
{\left[\mathrm{MJ} \times \mathrm{m}^{-2}\right]}\end{array}$ & 35.33 & 34.29 \\
\hline $\begin{array}{l}\text { Average mass lost rate (MLR) } \\
{\left[\mathrm{g} \times \mathrm{s} \times \mathrm{m}^{-2}\right]}\end{array}$ & 20.8 & 17.99 \\
\hline $\begin{array}{l}\text { Average specific extinction area } \\
(\mathrm{SEA})\left[\mathrm{m}^{2} \times \mathrm{kg}^{-1}\right]\end{array}$ & 1122.26 & 1180.56 \\
\hline Average $\mathrm{CO}$ yield $\left[\mathrm{kg} \times \mathrm{kg}^{-1}\right]$ & 0.0713 & 0.0769 \\
\hline Average $\mathrm{CO}_{2}$ yield $\left[\mathrm{kg} \times \mathrm{kg}^{-1}\right]$ & 2.2456 & 2.4157 \\
\hline $\begin{array}{l}\text { Fire hazard }\left(1 / \mathrm{t}_{\text {flasover }}\right) \\
{\left[\mathrm{kW} \times \mathrm{m}^{-2} \times \mathrm{s}^{-1}\right]}\end{array}$ & 25.29 & 21.10 \\
\hline $\begin{array}{l}\text { Relative toxic fire hazard } \\
\left(\mathrm{RTFH}_{\mathrm{CO} / \mathrm{CO} 2}\right)\end{array}$ & 0.0115 & 0.0113 \\
\hline
\end{tabular}

chlorine [9]. In the early stage of the combustion of vulcanizate containing the filler in question, hydrogen chloride is emitted considerably, impeding the ignition of filled elastomeric materials as indicated by the values of ignition temperature $\left(T_{\mathrm{Z}}\right)$. The sulfur vulcanizate of SBR rubber containing that filler shows a higher ignition temperature 
by about $30{ }^{\circ} \mathrm{C}$ in relation to the unfilled elastomer. The emitting hydrogen chloride also inhibits radical reactions taking place in flame, first of all, the oxidation of $\mathrm{CO}$ to $\mathrm{CO}_{2}$, which is the main source of heat during the combustion of polymers and polymeric materials (Table 3).

The results obtained by the cone calorimetry indicate that halloysite exerts an influence on the fire hazard posed by the elastomers containing this filler (Table 4). The smaller fire hazard of the nanocomposite of butadienestyrene rubber (SSH8), in relation to the unfilled sulfur vulcanizate of this rubber (SS), results from the comparison of parameters, such as the average heat emission rate $\left(\mathrm{HRR}_{\max }\right.$ and HRR), average specific combustion heat (HOC), and average mass loss rate (MLR). However, under the influence of the nanofiller, the average optical fume density is increased (SEA). This seems to result from the presence of carbon on the surface of aluminosilicate, facilitating the formation of carbon black, a main component of fume (Table 1).

\section{Conclusions}

Regardless of the structure of the spatial network of elastomers, the activated halloysite considerably decreases the rate of their decomposition under thermo-oxidative conditions, and consequently reduces the flammability of the nanocomposites under investigation as confirmed by OI, combustion time in air and ignition temperature. The latter parameter increases especially in the case of the vulcanizates containing the nucleus-sheath-type filler.

The reduced flammability of the nanocomposites investigated results from the excellent barrier properties of the nanoadditives used as well as from emitting $\mathrm{HCl}$ in the case of the nucleus-sheath type filler.

The use of the modified halloysite as filler of diene elastomers also allows the reduction in their fire hazard.

Open Access This article is distributed under the terms of the Creative Commons Attribution Noncommercial License which permits any noncommercial use, distribution, and reproduction in any medium, provided the original author(s) and source are credited.

\section{References}

1. Achilias DS, Nikolaidis AK, Karayannidis GP. PMMA/organomodified montmorillonite nanocomposites prepared by in situ bulk polymerization. J Therm Anal Calorim. 2010;102:451-60.
2. Lalikova S, Pajtasova M, Ondrusova D, Bazylakova T, Olsovsky M, Jona E, Mojumdar SC. Thermal and spectral properties of natural bentonites and their applications as reinforced nanofillers in polymeric materials. J Therm Anal Calorim. 2010;100:745-9.

3. Gilman W. Flammability and thermal stability studies of polymer layered-silicate (clay) nanocomposites. Appl Clay Sci. 1999;15: 31-49.

4. Handge UA, Hedicke-Hochstotter K, Altstadt V. Composites of polyamide 6 and silicate nanotubes of mineral halloysite: influence of molecular weight on thermal and rheological properties. Polymer. 2010;51:2690-9.

5. Guo B, Chen F, Lei Y, Liu X, Wan J, Jia D. Styrene-butadiene rubber/halloysite nanotubes nanocomposites modified by sorbic acid. Appl Surf Sci. 2009;255:7329-36.

6. Rooj S, Das A, Thakur V, Mahaling RN, Bhowmick AK, Heinrich G. Preparation and properties of natural nanocomposites based on natural rubber and naturally occurring halloysite nanotubes. Mater Des. 2010;31:2151-6.

7. Levis SR, Deasy PB. Characterisation of halloysite for use a microtublar drug delivery system. Int J Pharm. 2002;243:125-34.

8. Joussein E, Petit S, Delvaux B. Behavior of halloysite clay under formamide treatment. Appl Clay Sci. 2007;35:17-24.

9. Janowska G, Rzymski W, Kmiotek M, Kucharska A, Kasiczak A. Właściwości termiczne i palność chlorosulfonowanego polietylenu. Polimery. 2009;4:243-324.

10. Zhao M, Liu P. Halloysite nanotubes/polystyrene (HNTs/PS) nanocomposites via in situ bulk polymetrization. J Therm Anal Calorim. 2008;94:103-7.

11. Rybiński P, Janowska G. Influence of network structures of nitrile rubbers on their thermal properties. Polimery. 2009;54:275-82.

12. Janowska G, Rybiński P, Jantas R. Effect of the modification of silica on thermal properties and flammability of cross-linked butadiene-acrylonitrile rubbers. J Therm Anal Calorim. 2007;87: 511-7.

13. Rybiński P, Janowska G, Ślusarski L. Influence of cryogenic modification of silica on thermal properties and flammability of cross-linked nitrile rubber. J Therm Anal Calorim. 2010;101: 665-70.

14. Janowska G, Przygocki W, Włochowicz A. Palność polimerów i materiałów polimerowych WNT, Warszawa 2007, ISSBN: 978-83-204-3299-2, 340 stron.

15. Rybiński P, Janowska G. Effect of flame retardants on thermal stability and flammability of cured nitrile rubber. Polimery. 2009;11-12:833-9.

16. Leszczyńska A, Njuguna J, Pielichowski K, Benerjee JR. Polymer/montmorillonite nanocomposites with improved thermal properties. Part I. Thermochim Acta. 2007;453:75-96.

17. Janowska G, Kucharska-Jastrząbek A, Rybiński P. Thermal stability, flammability and fire hazard of butadiene-acrylonitrile rubber nanocomposites. J Therm Anal Calorim. doi:10.1007/s 10973-0101282-y

18. Marney DCO, Russell LJ, Wu DY, Nguyen T, Cramm D, Rigopoulos N, Wright N, Greaves M. The suitability of halloysite nanotubes as fire retardant for nylon 6. Polym Degrad Stab. 2008;93:1971-8.

19. Mingliang Du, Baochun Guo, Demin Jia. Thermal Stability and flame retardant effects of halloysite nanotubes on poly(propylene). Eur Polym J. 2006;42:1362-9. 